BMJ Open

Diabetes

Research

\& Care

\section{Non-adherence to eye care in people with diabetes}

To cite: Murchison AP, Hark L, Pizzi LT, et al. Nonadherence to eye care in people with diabetes. BMJ Open Diab Res Care 2017;5:e000333. doi:10.1136/ bmjdrc-2016-000333

Received 8 January 2017 Revised 31 May 2017 Accepted 5 June 2017

\section{CrossMark}

${ }^{1}$ Department of Research, Wills Eye Hospital, Philadelphia, Pennsylvania, USA

${ }^{2}$ Thomas Jefferson University, Philadelphia, Pennsylvania, USA

Correspondence to Ann P Murchison; amurchison@willseye.org

\section{ABSTRACT}

Objective Evaluate individual factors that impact adherence to eye care follow-up in patients with diabetes. Design and methods A 4-year retrospective chart review was conducted for 1968 patients with diabetes over age 40 from an urban academic center. Data collected included demographics, insurance, visual acuity, smoking status, medications, dates of dilated fundus examinations (DFE), and reported hemoglobin A1C and blood glucose levels. The primary outcome was timely DFE follow-up adherence following the initial eye exam visit.

Results Overall, $41.6 \%$ of patients adhered to initial follow-up eye care recommendations. Multivariable analysis demonstrated that patients with severe diabetic retinopathy (DR) were more adherent than patients with mild DR (OR 1.86). Other variables associated with increased adherence were visual impairment and reported A1C or blood glucose. Smoking was associated with decreased adherence. Ethnicity and insurance were also significantly associated with adherence. Longitudinal follow-up rates were influenced by additional factors, including ethnicity and neighborhood deprivation index. Conclusions Patients with moderate to severe DR and/ or visual impairment were more likely to adhere to timely DFE follow-up. This could relate to the presence of visual symptoms and/or other systemic manifestations of diabetes. Smokers were less likely to adhere to timely DFE follow-up. One hypothesis is patients who smoke have other symptomatic health problems which patients prioritize over asymptomatic ocular disorders. In order to reduce vision loss from $D R$, practitioners should be aware that patients with mild and moderate DR, patients with normal vision, and smokers are at greater risk for poor follow-up eye care adherence.

\section{INTRODUCTION}

Approximately, 285 million people worldwide have been diagnosed with diabetes. ${ }^{1}$ It is estimated that by 2025, 53.1 million Americans will be affected by diabetes, representing a projected increase of $64 \%$ from $2010 .{ }^{2}$ Diabetic retinopathy (DR) is the most common complication of diabetes and a leading cause of blindness in the USA and other countries. ${ }^{3}$ Almost all people with diabetes will develop some degree of DR, with incidence increasing with longer duration of diabetes. ${ }^{4}$ A retinal vascular disorder, DR results in microvascular damage and leads to retinal ischemia and

\section{Significance of this study}

What is already known about this subject?

- Factors known to impact overall eye care utilization include age, ethnicity, socioeconomic status, sex, and insurance status.

- Less than $60 \%$ of Americans with diabetes adhere to recommendations for annual eye exams.

What are the new findings?

- Multiple factors impacted adherence to eye exams in this population with diabetes, including severity of diabetic retinopathy, ethnicity, and reporting of hemoglobin A1C or blood sugar.

- Smoking status is a new risk factor impacting adherence in our population.

How might these results change the focus of research or clinical practice?

- Understanding the risk stratification for adherence in patients with diabetes may impact clinical recommendations.

increased vascular permeability. Estimates of DR and vision-threatening DR prevalence in US adults with diabetes are $28.5 \%$ and $4.4 \%$, respectively. ${ }^{5}$ In 2004, blindness from DR accounted for approximately US\$500 million in direct medical costs among Americans age 40 and older. ${ }^{6}$ Improving the detection, management, and treatment of DR could save between US $\$ 62.1$ and 108.6 million in annual costs to the federal government. ${ }^{4}$ Due to the advancing age of the population and growing rates of obesity across all ethnic groups, the medical and financial costs of diabetes and DR in the USA continue to rise. ${ }^{6}$

Management of DR includes early identification, regular eye examinations, aggressive control of hyperglycemia and hypertension, as well as medical and/or surgical ocular treatment(s). The American Diabetes Association and the American Academy of Ophthalmology recommend dilated fundus examinations (DFEs) for all people with diabetes at least once a year and more frequent exams for more advanced DR. ${ }^{78}$ However, only between $50 \%$ and $60 \%$ of Americans with 
diabetes receive annual DFEs, ${ }^{9}$ with rates even lower in underserved and racial/ethnic minority populations. ${ }^{10-12}$ In order to reduce the prevalence of eye disease and improve patients' quality of life, Healthy People 2020 aims to increase the proportion of adults with diabetes who have comprehensive eye examinations. ${ }^{9}$ One method to achieve this goal is to implement targeted interventions for patients at risk for low adherence. Studies have shown that age ${ }^{612-15}$ gender, ${ }^{12} 1416$ ethnicity, ${ }^{13-15}$ 17-19 socioeconomic status, ${ }^{61214171920}$ and insurance coverage ${ }^{616-1821-23}$ affect utilization of eye care services. However, limited research has documented the factors associated with adherence to established recommendations for DFE follow-up. Most research to date assessing DFE adherence has used survey methods. ${ }^{24}$ Self-reported data are limited not only due to response bias but also in the clinical variables that can be collected. In addition, most research has only assessed whether patients with diabetes receive an annual eye examination and does not take into account the severity of DR.

Therefore, this study aims to (1) identify factors associated with short-term adherence to DFE within a recommended time frame following an index visit for a large cohort of patients with diabetes in an urban eye care setting, (2) identify the factors that impact longitudinal utilization of DFE services and (3) compare the individual, clinical, and system-level factors that impact DFE follow-up adherence by severity of DR. With this data, we aim to identify the characteristics of patients at high risk for poor adherence to DFE follow-up.

\section{RESEARCH DESIGN AND METHODS}

Following institutional review board approval, a database was developed using billing and administrative information of patients over age 40 who had their initial visit to a general ophthalmology or retina clinic within an urban academic eye hospital between 1 January 2007 and 12 December 2010. Patients with diabetes were identified in the claims files using International Classification of Diseases, Ninth Revision (ICD-9) diagnosis codes for diabetes (250.xx) and/or DR (362.xx). At each encounter, patients were classified by their level of DR severity (mild, moderate, and severe) in the more severe eye using ICD codes documented in claims (table 1). Patients with diabetes without DR were included in the mild category based on same follow-up recommendations.

Patient charts were reviewed to determine additional clinical information and confirm eligibility. All chart reviewers were research assistants and coordinators trained in the review process using sample charts that had been reviewed by an ophthalmologist. After training, each reviewer's work was evaluated in detail and additional focused training was conducted to assure a standardized chart review process. Patient insurance status from their index visit was recorded from billing data. From the chart review, patients' first reported hemoglobin A1C (HbA1C) and blood sugar levels, age, gender, ethnicity, current smoking status, prescription for glasses, visual acuity, diagnosis of other eye diseases, dates of DFEs, and medications were recorded. Medications noted included insulin, non-insulin diabetes medication, medications to treat hypertension, medications to treat hyperlipidemia, and medications to treat the mental health conditions of anxiety and/or depression. An investigator with a doctorate in pharmacy compiled the list of all medications for each category. Best-corrected visual acuity (BCVA) in the worse eye was categorized as normal vision (20/60 or better) or visual impairment (20/70 or worse). Driving distance is calculated based on the calculations using the eye clinic and patient addresses. Socioeconomic status was estimated using a patient's home census tract based on a previously described standardized neighborhood deprivation index..$^{25}$ If ethnicity was not recorded in the chart, reviewers obtained it from the patient's driver's license when available. When ethnicity could not be determined from the chart or the driver's license, it was imputed using a previously validated approach based on patients' last names and 2010 Census tract location. ${ }^{26} 27$

The index visit was defined as the date of the first DFE in this eye care system including a diagnosis of type 1 or type 2 diabetes or DR. Patients who did not have a documented DFE at the designated eye clinics within 30 days of type 1 /type 2 diabetes or DR noted

Table 1 ICD-9 codes and American Academy of Ophthalmology recommended follow-up times for patients with diabetes stratified by severity of diabetic retinopathy ${ }^{8}$

\begin{tabular}{llll}
\hline Category & ICD-9 code and diagnosis & Recommended DFE follow-up & Acceptable DFE follow-up \\
\hline Mild & $250.00(\mathrm{DM})$ & 12 months & 15 months \\
& 362.01 Background NPDR & & \\
& 352.03 NOS NPDR & & 12 months \\
Moderate & 362.04 Mild NPDR & $6-12$ months & 4 months \\
& 362.05 Moderate NPDR & & $2-4$ months \\
Severe & 362.06 Severe NPDR & & \\
& 362.02 PDR & & \\
\hline
\end{tabular}

DFE, dilated fundus examination; DM, diabetes mellitus; ICD-9, International Classification of Diseases, Ninth Revision; NOS, not otherwise specified; NPDR; non-proliferative diabetic retinopathy; PDR, proliferative diabetic retinopathy. 
in their billing records were removed from the sample, as we were unable to define the index visit and hence the recommended follow-up time for these individuals. The diagnosis of diabetes did not have to be new to the patients. For the short-term adherence measure, subjects were defined as adherent if they obtained a DFE within the recommended time after their index visit. Acceptable follow-up was defined as within 15 months for mild DR, within 12 months for moderate $\mathrm{DR}$ and within 4 months from the index visit for severe DR (table 1).

This study also assessed longitudinal utilization of DFE services. Longitudinal utilization was measured by the number of DFEs per year over the 4-year study. After the index visit, the severity of DR and the date of each DFE follow-up visit were recorded over the 4-year period.

\section{Data analysis}

Descriptive statistics (frequencies, ranges, mean, SD) were calculated to summarize the sample characteristics. Associations between individual, clinical, system information, and DFE follow-up adherence were evaluated using $\chi^{2}$ tests. Logistic regression was used to evaluate the adjusted impact of individual, clinical, and system-level factors related to DFE follow-up adherence. All variables associated with adherence in the univariable analyses $(\mathrm{p}<0.20)$ were included in the multivariable logistic regression model, and a backward elimination procedure was used to sequentially remove non-significant terms until all variables had $p<0.20$. The number of DFEs over the entire follow-up period was modeled using Poisson regression with follow-up time as the offset term. The same variable selection procedure was used to develop a multivariable model as used for initial DFE adherence. Final multivariable logistic and Poisson models were developed for the entire cohort, for subjects classified with mild DR at the index visit, and for subjects classified with severe DR at the index visit. The distribution of time from index visit to first follow-up DFE was estimated using the Kaplan-Meier method. All analyses were performed using SAS V.9.2 or later (SAS Institute, Cary, North Carolina, USA).

\section{RESULTS}

Billing data indicated that 2238 patients with diabetes had an initial visit at the general ophthalmology or retina clinic between 1 January 2007 and 31 December 2010. Charts of 2179 patients were available for review. Additional patients were excluded who had a visit prior to $2007(n=23)$, no DFE within 30 days of the index visit $(n=128)$, or insufficient time between the index visit and review date to allow for recommended follow-up $(n=60)$, leaving a total of 1968 patients included in this study. The mean age of included patients was 59.4 years (SD 10.9 years) with a range of $40-93$ years. The median of follow-up time was 2.74 years (range of $0.70-5.72$ years).

\section{Adherence to initial DFE follow-up}

Overall, $41.6 \%$ of individuals were adherent to the initial recommended follow-up DFE after the index visit with an average of 0.61 DFEs per year over the entire follow-up period. Adherence to initial DFE follow-up and longitudinal utilization of DFE services were evaluated by patient characteristics (table 2). For initial DFE follow-up, severity of DR was significantly associated with adherence $(p<0.0001)$, with patients with mild DR being the least likely to follow-up in a timely manner. Over the 4-year period, $35.1 \%$ of patients with mild or no DR completed DFEs within the recommended follow-up time period (15 months) compared with $44.0 \%$ of patients with moderate DR (12 months) and $65.4 \%$ of patients with severe DR (4 months). The median time to initial follow-up was 21 days for severe patients, 127 days for moderate patients, and 246 days for mild patients. Patients under 65 years were less likely to adhere to follow-up recommendations than those over 65 ( $\mathrm{p}=0.0043)$. Patients with visual impairment in the worse eye were more adherent to follow-up than patients with normal vision $(\mathrm{p}<0.0001)$. Ethnicity also impacted adherence $(\mathrm{p}=0.0047)$ with adherence ranging from $40.73 \%$ to $47.37 \%$ by group. Smokers were less likely to follow-up than non-smokers $(p<0.0001)$. Other factors that were significantly associated with adherence to first DFE follow-up in the univariable analyses included the presence of HbAlC documentation $(\mathrm{p}<0.0001)$, blood sugar documentation $(\mathrm{p}<0.0001)$, insulin use $(p<0.0001)$, diagnosis of cataract $(p<0.0001)$, glaucoma $(\mathrm{p}=0.0053)$, non-diabetic retinal disease $(\mathrm{p}<0.0001)$, and other ocular comorbidities $(\mathrm{p}<0.0001)$. Insurance status $(\mathrm{p}=0.0008)$ was significantly associated with adherence with patients with Medicaid coverage having the lowest adherence for the first DFE follow-up. Absence of mental health medication use was also associated with higher adherence $(\mathrm{p}=0.013)$.

\section{Longitudinal utilization of DFE services}

As for adherence to DFE follow-up, severity of DR $(\mathrm{p}<0.0001)$, visual impairment in the worse eye $(\mathrm{p}<0.0001)$, HbA1C documentation $(\mathrm{p}<0.0001)$, blood sugar documentation $(\mathrm{p}<0.0001)$, smoking status $(\mathrm{p}<0.0001)$, insurance $(\mathrm{p}=0.0095)$, insulin use $(\mathrm{p}<0.0001)$, mental health medicine use $(\mathrm{p}<0.0001)$, non-diabetic retinal disease diagnosis $(\mathrm{p}<0.0001)$, and other ocular comorbidity diagnosis $(\mathrm{p}<0.0001)$ were significantly associated with number of DFEs per year in the univariable analysis (table 2). Insurance through Medicaid, current smoking and mental health medicine use were associated with lower utilization. The presence of all other factors was associated with higher use. In addition, ethnicity $(\mathrm{p}=0.0047)$, prescription for glasses $(p=0.0001)$, neighborhood deprivation index $(\mathrm{p}=0.0057)$, hyperlipidemia medication use $(\mathrm{p}=0.047)$, and driving distance $(\mathrm{p}=0.0066)$ were associated with number of DFEs per year but not with initial DFE follow-up. Patients of Asian race/ethnicity had the higher utilization than other groups as did those in the 
Table 2 DFE follow-up and longitudinal utilization univariable analysis by patient characteristics

\begin{tabular}{|c|c|c|c|c|c|c|}
\hline \multirow[b]{2}{*}{ Variable } & \multirow[b]{2}{*}{ Values } & \multirow[b]{2}{*}{$\mathbf{n}$} & \multicolumn{2}{|c|}{$\begin{array}{l}\text { Adherence to initial } \\
\text { follow-up }\end{array}$} & \multicolumn{2}{|c|}{$\begin{array}{l}\text { Number of DFEs per year over } \\
\text { entire follow-up period }\end{array}$} \\
\hline & & & n (\%) & p Value & $\begin{array}{l}\text { Mean } \\
(95 \% \mathrm{Cl})\end{array}$ & $p$ Value \\
\hline \multirow[t]{3}{*}{ Severity } & Severe & 393 & 257 (65.39) & $<0.0001$ & 1.45 (1.34 to 1.58$)$ & $<0.0001$ \\
\hline & Moderate & 107 & 47 (43.93) & & 0.54 (0.42 to 0.71$)$ & \\
\hline & Mild & 1468 & 515 (35.08) & & 0.39 (0.36 to 0.43$)$ & \\
\hline \multirow[t]{2}{*}{ Gender } & $\mathrm{F}$ & 1077 & $432(40.11)$ & 0.13 & 0.58 (0.54 to 0.64$)$ & 0.16 \\
\hline & M & 890 & $387(43.48)$ & & 0.64 (0.58 to 0.70$)$ & \\
\hline \multirow[t]{2}{*}{ Age } & $<65$ & 1369 & $541(39.52)$ & 0.0043 & 0.61 (0.57 to 0.66$)$ & 0.70 \\
\hline & $\geq 65$ & 599 & $278(46.41)$ & & 0.60 (0.53 to 0.67$)$ & \\
\hline \multirow[t]{4}{*}{ Ethnicity/race } & African-American & 1321 & $538(40.73)$ & 0.58 & 0.57 (0.53 to 0.62$)$ & 0.0047 \\
\hline & Asian & 76 & $36(47.37)$ & & 0.93 (0.72 to 1.19$)$ & \\
\hline & Caucasian & 391 & 164 (41.94) & & 0.59 (0.51 to 0.68$)$ & \\
\hline & Latino/Hispanic & 139 & $62(44.6)$ & & 0.69 (0.55 to 0.86$)$ & \\
\hline \multirow[t]{2}{*}{ BCVA in worse eye } & $\begin{array}{l}\text { Normal vision }(20 / 60 \text { or } \\
\text { better) }\end{array}$ & 1369 & 455 (33.24) & $<0.0001$ & 0.44 (0.40 to 0.48$)$ & $<0.0001$ \\
\hline & $\begin{array}{l}\text { Visual impairment (20/70 or } \\
\text { worse) }\end{array}$ & 537 & $339(63.13)$ & & 1.05 (0.96 to 1.15$)$ & \\
\hline \multirow[t]{2}{*}{$\mathrm{HbA1c}$ in chart } & Yes & 482 & $244(50.62)$ & $<0.0001$ & 0.90 (0.82 to 1.00$)$ & $<0.0001$ \\
\hline & No & 1486 & 575 (38.69) & & 0.51 (0.48 to 0.56$)$ & \\
\hline \multirow[t]{2}{*}{ Blood sugar in chart } & Yes & 1350 & $612(45.33)$ & $<0.0001$ & 0.70 (0.65 to 0.75$)$ & $<0.0001$ \\
\hline & No & 618 & 207 (33.5) & & 0.42 (0.36 to 0.48$)$ & \\
\hline \multirow[t]{2}{*}{ Wears glasses } & Yes & 1257 & $500(39.78)$ & 0.11 & 0.54 (0.5 to 0.59$)$ & 0.0001 \\
\hline & No & 675 & $294(43.56)$ & & 0.7 (0.64 to 0.78$)$ & \\
\hline \multirow{2}{*}{$\begin{array}{l}\text { Current smoking } \\
\text { status }\end{array}$} & Yes & 406 & $117(28.82)$ & $<0.0001$ & 0.4 (0.33 to 0.47$)$ & $<0.0001$ \\
\hline & No & 1537 & $697(45.35)$ & & 0.67 (0.63 to 0.72 ) & \\
\hline \multirow[t]{5}{*}{ Insurance } & No insurance & 340 & $147(43.24)$ & 0.0008 & 0.69 (0.6 to 0.8 ) & 0.0095 \\
\hline & Medicaid & 555 & $199(35.86)$ & & 0.52 (0.45 to 0.59$)$ & \\
\hline & Medicare & 413 & 204 (49.39) & & 0.66 (0.58 to 0.75$)$ & \\
\hline & Medicaid+Medicare & 40 & $14(35)$ & & 0.4 (0.23 to 0.71$)$ & \\
\hline & Private/other/vision & 620 & $255(41.13)$ & & 0.62 (0.55 to 0.69$)$ & \\
\hline \multirow{4}{*}{$\begin{array}{l}\text { Neighborhood } \\
\text { deprivation index }\end{array}$} & 1 (low SES) & 1375 & $561(40.8)$ & 0.27 & 0.58 (0.54 to 0.63$)$ & 0.0057 \\
\hline & 2 & 345 & $146(42.32)$ & & 0.75 (0.65 to 0.85$)$ & \\
\hline & 3 & 138 & $68(49.28)$ & & 0.49 (0.38 to 0.64$)$ & \\
\hline & 4 (high SES) & 110 & $44(40)$ & & 0.62 (0.47 to 0.81$)$ & \\
\hline \multirow[t]{2}{*}{ Medications (insulin) } & Yes & 571 & $280(49.04)$ & $<0.0001$ & 0.75 (0.68 to 0.83 ) & $<0.0001$ \\
\hline & No & 1397 & 539 (38.58) & & 0.55 (0.51 to 0.59$)$ & \\
\hline \multirow{2}{*}{$\begin{array}{l}\text { Medications } \\
\text { (diabetes) }\end{array}$} & Yes & 1507 & $624(41.41)$ & 0.73 & 0.59 (0.55 to 0.64$)$ & 0.13 \\
\hline & No & 461 & $195(42.3)$ & & 0.66 (0.58 to 0.75$)$ & \\
\hline \multirow{2}{*}{$\begin{array}{l}\text { Medications } \\
\text { (hypertension) }\end{array}$} & Yes & 1230 & $522(42.44)$ & 0.34 & 0.60 (0.55 to 0.65$)$ & 0.54 \\
\hline & No & 738 & $297(40.24)$ & & 0.62 (0.56 to 0.69$)$ & \\
\hline \multirow{2}{*}{$\begin{array}{l}\text { Medications } \\
\text { (hyperlipidemia) }\end{array}$} & Yes & 742 & $322(43.4)$ & 0.21 & 0.56 (0.5 to 0.62$)$ & 0.047 \\
\hline & No & 1226 & $497(40.54)$ & & 0.64 (0.59 to 0.69 ) & \\
\hline \multirow{2}{*}{$\begin{array}{l}\text { Medications (mental } \\
\text { health) }\end{array}$} & Yes & 242 & $83(34.30)$ & 0.013 & 0.41 (0.33 to 0.51$)$ & $<0.0001$ \\
\hline & No & 1666 & $712(42.74)$ & & 0.64 (0.60 to 0.68$)$ & \\
\hline
\end{tabular}




\begin{tabular}{|c|c|c|c|c|c|c|}
\hline \multirow[b]{2}{*}{ Variable } & \multirow[b]{2}{*}{ Values } & \multirow[b]{2}{*}{$\mathbf{n}$} & \multicolumn{2}{|c|}{$\begin{array}{l}\text { Adherence to initial } \\
\text { follow-up }\end{array}$} & \multicolumn{2}{|c|}{$\begin{array}{l}\text { Number of DFEs per year over } \\
\text { entire follow-up period }\end{array}$} \\
\hline & & & n (\%) & p Value & $\begin{array}{l}\text { Mean } \\
(95 \% \mathrm{Cl})\end{array}$ & p Value \\
\hline \multirow[t]{3}{*}{ Driving distance } & $0-5$ miles & 665 & $278(41.8)$ & 0.40 & 0.52 (0.47 to 0.59$)$ & 0.0066 \\
\hline & 5-25 miles & 1116 & $455(40.77)$ & & 0.66 (0.6 to 0.71$)$ & \\
\hline & $\geq 25$ miles & 187 & $86(45.99)$ & & $0.62(0.51$ to 0.76$)$ & \\
\hline \multirow[t]{2}{*}{ Cataract } & Yes & 321 & 168 (52.34) & $<0.0001$ & 0.67 (0.57 to 0.78$)$ & 0.21 \\
\hline & No & 1647 & $651(39.53)$ & & $0.60(0.56$ to 0.64$)$ & \\
\hline \multirow[t]{2}{*}{ Glaucoma } & Yes & 192 & $98(51.04)$ & 0.0053 & 0.68 (0.56 to 0.82$)$ & 0.26 \\
\hline & No & 1776 & 721 (40.6) & & 0.60 (0.56 to 0.64$)$ & \\
\hline \multirow{2}{*}{$\begin{array}{l}\text { Non-diabetic retinal } \\
\text { disease }\end{array}$} & Yes & 203 & $156(76.85)$ & $<0.0001$ & 1.46 (1.3 to 1.64$)$ & $<0.0001$ \\
\hline & No & 1765 & $663(37.56)$ & & $0.5(0.47$ to 0.54$)$ & \\
\hline \multirow{2}{*}{$\begin{array}{l}\text { Other ocular } \\
\text { comorbidity }\end{array}$} & Yes & 1222 & $568(46.48)$ & $<0.0001$ & 0.71 (0.65 to 0.76$)$ & $<0.0001$ \\
\hline & No & 746 & 251 (33.65) & & $0.46(0.41$ to 0.51$)$ & \\
\hline
\end{tabular}

Bold indicates $p$ values that reach significance.

DFE, dilated fundus exam; BCVA, best-corrected visual acuity; HbA1c,hemoglobin A1c; SES, socioeconomic status.

second quartile of SES, those closest to Wills, and those not using hyperlipidemia medications.

\section{Multivariable analysis of factors affecting initial DFE follow- up overall and by severity of DR}

In the final multivariable logistic regression model of the full cohort, severity of DR, visual impairment in the worse eye, HbA1C documentation, blood sugar documentation, smoking status, diagnosis of cataract, glaucoma, non-diabetic retinal disease, and other ocular comorbidities were significantly associated with initial DFE follow-up adherence (table 3). Patients with severe DR had 1.86 times (95\% CI 1.39 to 2.50 ) higher odds of adherence to initial follow-up recommendations than patients with mild DR.

Patients with severe DR, over age 65 were less likely than younger patients to follow-up (OR 0.57; 95\% CI 0.33 to 1.00). In patients with mild DR, visual impairment in the worse eye $(\mathrm{p}<0.0001)$, HbA1C documentation $(\mathrm{p}<0.0001)$, blood sugar documentation $(\mathrm{p}<0.0001)$, negative smoking status $(\mathrm{p}<0.0001)$, diagnosis of cataract $(p=0.012)$, glaucoma $(p=0.032)$, non-diabetic retinal disease $(\mathrm{p}<0.0001)$, or other ocular comorbidities $(p=0.0032)$ were associated with a higher likelihood of adhering to initial DFE follow-up recommendations. In patients with severe DR, only age $(\mathrm{p}=0.049)$, visual impairment in the worse eye $(\mathrm{p}=0.0018)$, blood sugar documentation $(\mathrm{p}=0.0038)$, and non-diabetic retinal disease diagnosis $(\mathrm{p}=0.030)$ were associated with increased likelihood of adherence to initial DFE follow-up.

\section{Multivariable analysis of factors affecting Iongitudinal utilization overall and by severity of DR}

In the full sample, the multivariable Poisson regression model for longitudinal utilization revealed that severity of DR ( $\mathrm{p}<0.0001)$, ethnicity ( $\mathrm{p}=0.028)$, visual impairment in the worse eye $(p<0.0001)$, HbAlC documentation $(p<0.0001)$, blood sugar documentation $(p<0.0001)$, smoking status $(\mathrm{p}<0.0001)$, non-diabetic retinal disease $(\mathrm{p}<0.0001)$, other ocular comorbidities $(\mathrm{p}<0.0001)$, and neighborhood deprivation index (NDI) $(\mathrm{p}=0.032)$ were associated with longitudinal utilization of DFE services (table 4). Patients with severe DR had 2.77 times (95\% CI 2.36 to 3.24) as many DFE appointments per year compared with patients with mild or no DR. Patients with visual impairment in the worse eye had 1.37 times (95\% CI 1.19 to 1.57 ) as many DFE appointments per year as patients with normal vision. Patients with HbA1C and blood sugar documentation had 1.65 times $(95 \% \mathrm{CI}$ 1.47 to 1.86 and 1.43 to 1.89 ) as many DFE appointments as patients without documentation, respectively. Patients who smoke had 0.72 times (95\% CI 0.61 to 0.85 ) as many DFEs per year as non-smokers.

When stratifying by severity, ethnicity $(\mathrm{p}=0.0052)$, visual impairment in the worse eye $(\mathrm{p}<0.001)$, NDI $(\mathrm{p}=0.015)$, and diagnosis of other ocular comorbidity $(\mathrm{p}=0.0006)$ were associated with longitudinal utilization in patients with mild DR but not in patients with severe disease. All factors associated with longitudinal utilization in patients with severe DR were also associated with longitudinal utilization in patients with mild DR.

\section{CONCLUSIONS}

In our sample, rates of adherence to follow-up DFE recommendations were disappointingly low across all ages and ethnic groups, ranging from $35 \%$ to $65 \%$ adherence depending on the severity of DR. Longitudinal utilization was also below recommendations, with the annual DFE rate being substantially less than 1 DFE per year for patients with mild and moderate DR and less than 2 DFEs per year for patients with severe DR. 


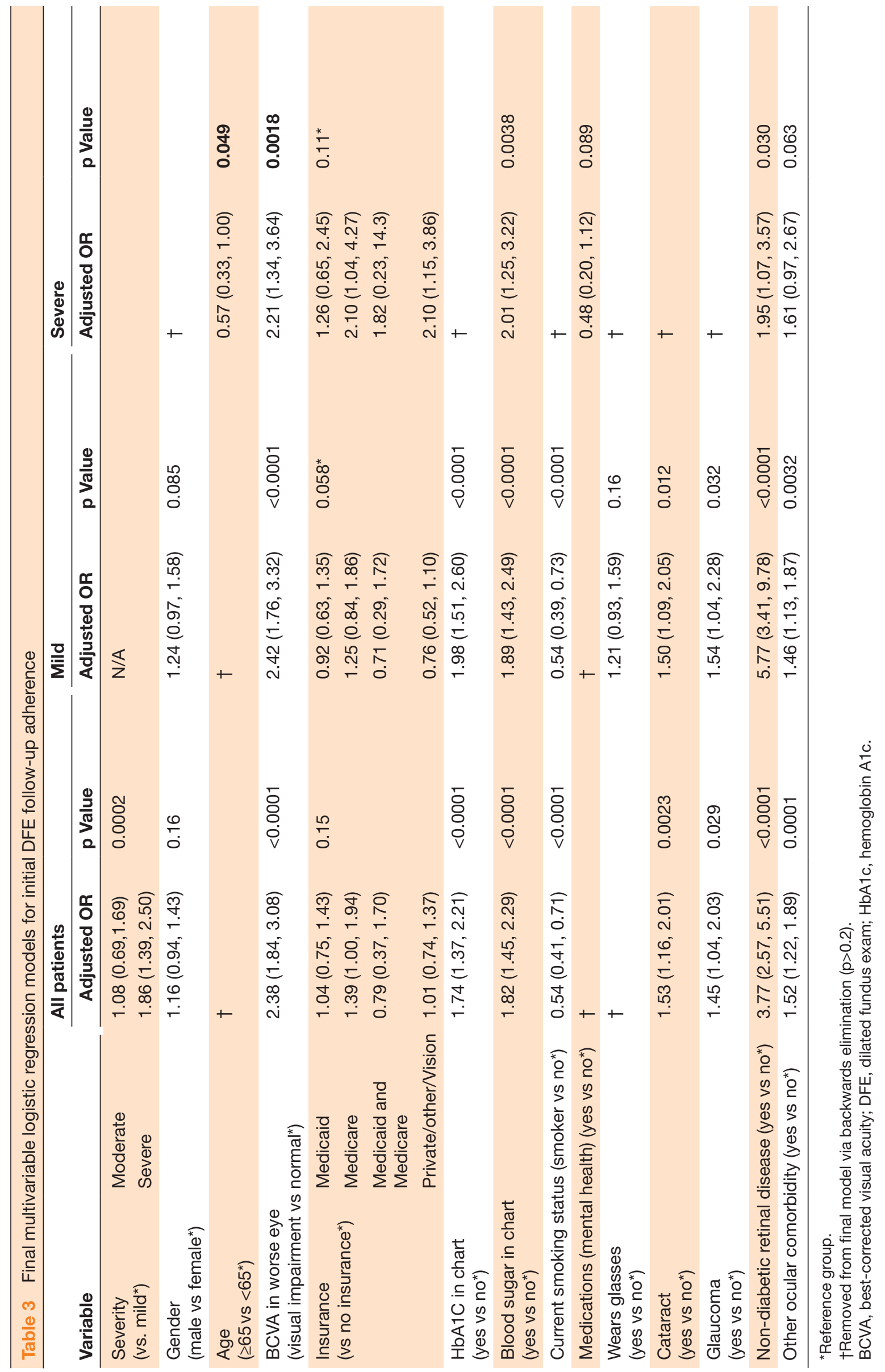


Table 4 Final multivariable Poisson regression models for total number of DFEs over the follow-up period

\begin{tabular}{|c|c|c|c|c|c|c|c|}
\hline \multirow{2}{*}{ Variable } & & \multicolumn{2}{|l|}{ All patients } & \multicolumn{2}{|l|}{ Mild } & \multicolumn{2}{|l|}{ Severe } \\
\hline & & Adjusted IRR & p Value & Adjusted IRR & p Value & Adjusted IRR & p Value \\
\hline \multirow{2}{*}{$\begin{array}{l}\text { Severity } \\
(\text { vs mild })\end{array}$} & Moderate & $1.30(0.96,1.76)$ & $<0.0001$ & & & & \\
\hline & Severe & $2.77(2.36,3.24)$ & & & & & \\
\hline \multicolumn{2}{|c|}{$\begin{array}{l}\text { Gender } \\
(\text { male vs female*) }\end{array}$} & $1.10(0.99,1.23)$ & 0.085 & $\dagger$ & & $\dagger$ & \\
\hline \multirow{3}{*}{$\begin{array}{l}\text { Ethnicity/race } \\
\text { (vs African- } \\
\text { American*) }\end{array}$} & Asian & $1.22(0.91,1.63)$ & 0.028 & $0.86(0.54,1.38)$ & 0.0052 & $1.55(0.97,2.47)$ & 0.14 \\
\hline & Caucasian & $0.84(0.69,1.03)$ & & $0.76(0.58,0.99)$ & & $0.98(0.68,1.43)$ & \\
\hline & Latino/Hispanic & $1.07(0.83,1.37)$ & & $1.30(0.97,1.74)$ & & $0.95(0.58,1.55)$ & \\
\hline \multicolumn{2}{|l|}{$\begin{array}{l}\text { Age } \\
\left(\geq 65 \text { vs }<65^{\star}\right)\end{array}$} & $\dagger$ & & $1.11(0.96,1.29)$ & 0.15 & $0.81(0.63,1.05)$ & 0.10 \\
\hline \multicolumn{2}{|c|}{$\begin{array}{l}\text { BCVA in worse eye } \\
\text { (visual impairment vs normal*) }\end{array}$} & $1.37(1.19,1.57)$ & $<0.0001$ & $1.54(1.31,1.81)$ & $<0.0001$ & $\dagger$ & \\
\hline \multicolumn{2}{|c|}{$\begin{array}{l}\text { HbA1C documented } \\
\text { (yes vs no*) }\end{array}$} & $1.65(1.47,1.86)$ & $<0.0001$ & $1.71(1.48,1.97)$ & $<0.0001$ & $1.54(1.21,1.97)$ & 0.0006 \\
\hline \multicolumn{2}{|c|}{$\begin{array}{l}\text { Blood sugar documented } \\
\text { (yes vs no*) }\end{array}$} & $1.65(1.43,1.89)$ & $<0.0001$ & $1.62(1.36,1.93)$ & $<0.0001$ & $1.55(1.20,2.00)$ & 0.0006 \\
\hline \multicolumn{2}{|l|}{$\begin{array}{l}\text { Wears glasses } \\
\text { (yes vs no*) }\end{array}$} & $1.12(0.99,1.26)$ & 0.072 & $\dagger$ & & $\dagger$ & \\
\hline \multicolumn{2}{|c|}{$\begin{array}{l}\text { Current smoking status } \\
\text { (smoker vs no*) }\end{array}$} & $0.72(0.61,0.85)$ & $<0.0001$ & $0.760 .63,0.91)$ & 0.0020 & $0.70(0.49,1.01)$ & 0.049 \\
\hline \multicolumn{2}{|c|}{$\begin{array}{l}\text { Medication (Insulin) } \\
\text { (yes vs no*) }\end{array}$} & $1.10(0.97,1.26)$ & 0.15 & $1.14(0.99,1.33)$ & 0.076 & $\dagger$ & \\
\hline \multicolumn{2}{|c|}{$\begin{array}{l}\text { Non-insulin diabetic } \\
\text { medication } \\
\text { (yes vs no*) }\end{array}$} & $0.87(0.75,1.01)$ & 0.069 & $\dagger$ & & $\dagger$ & \\
\hline \multicolumn{2}{|c|}{$\begin{array}{l}\text { Medications (mental health) } \\
\text { (yes vs no*) }\end{array}$} & $0.82(0.67,1.01)$ & 0.051 & $\dagger$ & & $0.60(0.34,1.08)$ & 0.070 \\
\hline \multicolumn{2}{|l|}{$\begin{array}{l}\text { Cataract } \\
\text { (yes vs no*) }\end{array}$} & $1.12(0.97,1.30)$ & 0.13 & $1.16(0.98,1.38)$ & 0.090 & $\dagger$ & \\
\hline \multicolumn{2}{|l|}{$\begin{array}{l}\text { Glaucoma } \\
\text { (yes vs no*) }\end{array}$} & $\dagger$ & & $1.23(0.99,1.53)$ & 0.067 & $\dagger$ & \\
\hline \multicolumn{2}{|c|}{$\begin{array}{l}\text { Non-diabetic retinal disease } \\
\text { (yes vs no*) }\end{array}$} & $1.71(1.49,1.96)$ & $<0.0001$ & $2.27(1.89,2.73)$ & $<0.0001$ & $1.38(1.09,1.74)$ & 0.0089 \\
\hline \multicolumn{2}{|c|}{$\begin{array}{l}\text { Other ocular comorbidity } \\
\text { (yes vs no*) }\end{array}$} & $1.27(1.13,1.44)$ & $<0.0001$ & $1.28(1.11,1.47)$ & 0.0006 & $\dagger$ & \\
\hline \multirow{3}{*}{$\begin{array}{l}\text { Neighborhood } \\
\text { deprivation } \\
\text { index } \\
\text { (vs lowest } \\
\text { quartile) }\end{array}$} & Moderately low & $1.17(0.97,1.41)$ & 0.032 & $1.08(0.86,1.36)$ & 0.015 & $1.17(0.81,1.70)$ & 0.20 \\
\hline & $\begin{array}{l}\text { Moderately } \\
\text { high }\end{array}$ & $0.81(0.59,1.12)$ & & $0.96(0.68,1.38)$ & & $0.70(0.36,1.35)$ & \\
\hline & High & $0.95(0.68,1.33)$ & & $0.54(0.31,0.93)$ & & $1.17(0.67,2.05)$ & \\
\hline \multirow{2}{*}{$\begin{array}{l}\text { Driving } \\
\text { distance } \\
\text { (vs 0-5 miles) }\end{array}$} & 5-25 miles & $1.01(0.87,1.17)$ & 0.15 & $\dagger$ & & $1.10(0.80,1.51)$ & 0.10 \\
\hline & $\geq 25$ miles & $0.83(0.64,1.07)$ & & & & $0.76(0.47,1.22)$ & \\
\hline
\end{tabular}

${ }^{*}$ Reference group.

†Removed from final model via backwards elimination ( $p>0.2)$.

Bold indicates $p$ values that reach significance.

BCVA, best-corrected visual acuity; DFE, dilated fundus exam; HbA1c, hemoglobin A1c; IRR, incidence rate ratio.

For over two decades, it has been well known that early identification and treatment can prevent at least $50 \%$ of severe vision loss in patients with DR. ${ }^{28}$ Previous studies have evaluated eye care utilization associations on a population level based on self-reported data, but this is the first study to analyze clinical and demographic characteristics of patients who do and do not adhere to follow-up DFE guidelines in a large, urban academic 
setting. This is also the first study to examine DFE adherence by severity of DR and the individual, clinical, and system-level factors that impact longitudinal utilization of DFE services.

\section{Statistically significant variables after adjustment}

Our results indicate that severity of DR is independently and strongly associated with adherence to timely DFEs. Specifically, patients with mild or no DR were the least likely to adhere to follow-up recommendations. We hypothesize several reasons for this association. First, patients with mild DR might not seek regular ophthalmic care because of a lack of perceived need-particularly because visual symptoms may be minimal or absent and lower severity of DR is associated with fewer systemic manifestations. ${ }^{29}$ In addition, up to half of individuals with moderate-to-severe visual loss do not seek regular eye care because they do not perceive a need for care. ${ }^{1830}$ It is also possible that patients in our study with mild or no DR had less contact with medical professionals perhaps due to being generally younger and having less time available due to competing commitments (eg, work or family). Thus, they may have less encouragement to regularly follow-up with their eye care provider. Lastly, there could be other factors not yet explored. Therefore, this association identifies a population that can be targeted with educational interventions to increase rates of eye care utilization among people with diabetes.

Population-based studies have consistently found diabetic eye care utilization to be associated with visual impairment. ${ }^{12-14}$ In our population, after adjusting for known risk factors, patients with visual impairment were more likely than patients with normal vision to adhere to initial follow-up DFE recommendations and use DFE services longitudinally. Presumably, visual loss motivates patients to obtain eye care.

Our study is also the first to find a relationship between smoking status and adherence with diabetic eye care: smokers were less likely than non-smokers to adhere to the recommended DFE follow-up and smokers had lower longitudinal utilization of DFE services, even when controlling for other variables. Smoking is related to multiple microvascular complications of diabetes, although smoking's specific effect on retinopathy has not been well defined. ${ }^{31}$ Smoking has also been directly linked to two of the leading causes of vision loss, cataracts, and macular degeneration, ${ }^{32}$ and may contribute to glaucoma. ${ }^{33}$ Smokers have been shown to use more healthcare services at a higher cost than non-smokers, which is in contrast to our findings of lower eye care utilization among individuals with diabetes who smoke. ${ }^{34}$ It is unclear why smoking is independently associated with less follow-up adherence. Perhaps, patients who smoke have other symptomatic health problems which patients give priority over asymptomatic or less symptomatic ocular disorders. People with diabetes who smoke may place less value on eye care given that smokers have worse overall health compared with non-smokers, leading to other illnesses superseding the perceived need for eye examinations. ${ }^{35}$ Smokers also tend to be less educated than non-smokers and may not understand the importance of known health recommendations, which may contribute to the differences between the groups. ${ }^{36}$ Additionally, self-management of diabetes is difficult, as attested to in multiple studies and addictions such as nicotine may impact self-management strategies.

Whether or not self-reported HbA1C or blood glucose was mentioned in a patient's chart was found to be significantly associated with DFE adherence rates and with increased longitudinal utilization, which was unexpected. ${ }^{37}$ Since HbA1C and blood glucose were from patient's self-report, it is possible that these patients are, in general, more informed and involved in their healthcare and therefore more likely to adhere to recommendations. However, since three-quarters of our patients were missing HbA1C values and one-third of patients were missing blood glucose, we did not evaluate relationships between level of $\mathrm{HbA1C}$ or blood glucose and adherence or other variables. While an objective marker of diabetes control would have been useful, the data could not be correlated with actual HbA1C or blood glucose, as it was subject to recall bias.

Caucasian ethnicity has been associated with higher rates of DFEs compared with African-Americans and Latinos with diabetes, ${ }^{10} 13141618$ which is particularly concerning as African-Americans and Latinos are projected to have the largest increase in prevalence of diabetic eye disease. ${ }^{6}$ However, ethnic status has not been found to be independently associated with DFE rates in all studies. ${ }^{11}$ In this current investigation, there was only an association between ethnicity and longitudinal utilization in patients with mild DR, with Asians having the most DFEs per year. Adherence to follow-up recommendations was consistently low across all ethnic/racial groups as shown in table 2 .

\section{Non-statistically significant variables after adjustment}

Insurance status is another variable that has been associated with DFE rates in population studies with sizeable proportions of patients without insurance status or access to free care. ${ }^{1216-182124}$ One study also found that among individuals with diabetes over 65 years of age, people who were dual eligible for Medicare and Medicaid were significantly less likely to receive DFEs compared with people eligible for Medicare alone (63\% vs $75 \%$; $\mathrm{p}<0.0001) .{ }^{20}$ We found insurance status to be associated with adherence rates and longitudinal utilization in the univariable analysis, with Medicaid patients having the lowest adherence rates and Medicare patients having the highest adherence rates. However, this association was not significant in multivariable analyses.

Several previous studies have found higher socioeconomic status (SES) to be associated with having DFEs. ${ }^{11} 1224$ In a national representative sample of 84572 people, Brechner et al found that in people with insulin-dependent diabetes and annual incomes 
over US $\$ 40000,72.9 \%$ had DFEs within the last year compared with $32.4 \%$ of people who had annual income less than US\$10 $000 .{ }^{11}$ We found SES was only associated with longitudinal utilization in patients with mild DR, not in initial DFE follow-up, and that patients of the two lower SES brackets had the most DFEs per year. Our findings could be real or due to the fact that we imputed SES using each subject's census tract location and dividing the census tracts for our patients into four quartiles based on relative SES. While this method for estimating SES has been previously validated, it is limited by relying on a patient's address and it cannot differentiate SES of individual people living in the same census tract.

Gender has been significantly associated with different DFE rates in a number of studies, with women consistently having higher rates of eye care compared with men. ${ }^{12} 1416$ This difference has been attributed to perceived need of care by each gender. According to the Behavioral Risk Factor Surveillance System, $42 \%$ of men with moderate-to-severe vision loss reported no need to have an eye examination compared with $29 \%$ of women with similar vision loss. ${ }^{22}$ However, our study found no differences in initial follow-up or eye care utilization between men and women. Our results agree with a recent study from Paskin-Hall et al, who also found gender was not significantly associated with annual DFE adherence. ${ }^{24}$

Distance from a healthcare facility or provider can be a barrier to care. Increased driving distance has been associated with poor glycemic control ${ }^{38} 39$ and lower use of insulin. ${ }^{40}$ One study found that people residing more than 10 miles from a diabetes management center were almost twice as likely to have HbA1C $>7 \%$ compared with people living closer to the care center. ${ }^{39}$ In contrast, we only found an association between driving distance and longitudinal utilization in severe patients, with patients living 5-25 miles within our healthcare facility having the most DFEs per year. Patients living within 5 miles of our facility are more likely to be from medically underserved areas than patients living slightly further away. In addition, our population was in an urban area with a large public transportation system. Previous studies linking driving distance to decreased care utilization have been predominantly conducted in rural areas where public transportation is minimal or absent.

\section{Strengths and weaknesses}

The strengths of our study include the large urban population followed over 4 years, the ability to determine DFE adherence based on objective data rather than self-report, and the ophthalmology clinical setting, which has not been previously characterized in terms of factors associated with adherence to follow-up eye care.

Weaknesses of our study included limited data concerning self-reported HbA1C levels and ethnicity, although we were able to impute ethnicity using a validated method. ${ }^{27}$ Another potential weakness is that we were only able to capture DFEs at our clinics. It is possible that some patients received follow-up eye care outside our clinics that was not captured in our data. Finally, although we attempted to gather extensive patient information, as an observational study, there is a potential for unmeasured confounding of associations.

The results of this study have important clinical and public health implications. Primary care practitioners, diabetic specialists, and eye care providers in urban clinical settings should identify people with diabetes at risk for poor follow-up in order to improve adherence rates, particularly:

- patients with normal vision;

- older patients with severe DR;

- patients with mild DR and no history of other eye diseases;

- patients with no ophthalmology documented HbA1C or blood glucose;

- smokers.

Population-based health programs can also target this cohort with specific educational interventions in order to increase eye care utilization among people with diabetes and attenuate the potential for severe visual disability from DR. While all patients with diabetes need to improve follow-up, targeting subgroups with low adherence rates could have a high impact and prevent progression to more severe DR.

Acknowledgements We would like to acknowledge the staff of the Wills Eye Hospital, Department of Research, especially Chelsea Aleo, for her help with this study.

Contributors All authors equally contributed to the data analysis and writing of this paper.

Competing interests None declared.

Patient consent None declared.

Ethics approval Wills Eye Hospital IRB.

Provenance and peer review Not commissioned; externally peer reviewed.

Open Access This is an Open Access article distributed in accordance with the Creative Commons Attribution Non Commercial (CC BY-NC 4.0) license, which permits others to distribute, remix, adapt, build upon this work non-commercially, and license their derivative works on different terms, provided the original work is properly cited and the use is non-commercial. See: http://creativecommons.org/ licenses/by-nc/4.0/

(C) Article author(s) (or their employer(s) unless otherwise stated in the text of the article) 2017. All rights reserved. No commercial use is permitted unless otherwise expressly granted.

\section{REFERENCES}

1. Shaw JE, Sicree RA, Zimmet PZ. Global estimates of the prevalence of diabetes for 2010 and 2030. Diabetes Res Clin Pract 2010;87:4-14.

2. Rowley WR, Bezold C. Creating public awareness: state 2025 diabetes forecasts. Popul Health Manag 2012;15:194-200.

3. Klein BE. Overview of epidemiologic studies of diabetic retinopathy. Ophthalmic Epidemiol 2007;14:179-83.

4. Schoenfeld ER, Greene JM, Wu SY, et al. Patterns of adherence to diabetes vision care guidelines: baseline findings from the Diabetic Retinopathy Awareness Program. Ophthalmology 2001;108:563-71.

5. Zhang X, Saaddine JB, Chou CF, et al. Prevalence of diabetic retinopathy in the United States, 2005-2008. JAMA 2010;304:649-56.

6. Saaddine JB, Honeycutt AA, Narayan KM, et al. Projection of diabetic retinopathy and other major eye diseases among people with diabetes mellitus: United States, 2005-2050. Arch Ophthalmol 2008;126:1740-7. 
7. Fong DS, Aiello L, Gardner TW, et al. Diabetic retinopathy. Diabetes Care 2003;26:226-9.

8. Preferred practice pattern guidelines for diabetic retinopathy American academy of ophthalmology. http://www.aao.org/preferredpractice-pattern/diabetic-retinopathy-ppp--2014 (accessed 18 Jan 2016).

9. U.S. Department of Health and Human Services, Office of Disease Prevention and Health Promotion. Healthy people 2020. http://www. healthypeople.gov/2020/topicsobjectives2020/objectiveslist.aspx? topicld $=8 \# 350$ (accessed 2 Feb 2016).

10. Kuo S, Fleming BB, Gittings NS, et al. Trends in care practices and outcomes among medicare beneficiaries with diabetes. Am J Prev Med 2005;29:396-403.

11. Brechner RJ, Cowie CC, Howie LJ, et al. Ophthalmic examination among adults with diagnosed diabetes mellitus. JAMA 1993;270:1714-8.

12. Zhang X, Saaddine JB, Lee PP, et al. Eye care in the United States: do we deliver to high-risk people who can benefit most from it? Arch Ophthalmol 2007;125:411-8.

13. Orr $\mathrm{P}$, Barrón $\mathrm{Y}$, Schein $\mathrm{OD}$, et al. Eye care utilization by older Americans: the SEE project. Salisbury Eye evaluation. Ophthalmology 1999;106:904-9.

14. Wang F, Javitt JC. Eye care for elderly Americans with diabetes mellitus. Failure to meet current guidelines. Ophthalmology 1996;103:1744-50.

15. Zhang X, Cotch MF, Ryskulova A, et al. Vision health disparities in the United States by race/ethnicity, education, and economic status: findings from two nationally representative surveys. Am J Ophthalmol 2012;154:S53-S62.e1e51-S62.e1.

16. Puent $\mathrm{BD}$, Klein BE, Klein R, et al. Factors related to vision care in an older adult cohort. Optom Vis Sci 2005;82:612-6.

17. Nelson KM, Chapko MK, Reiber G, et al. The association between health insurance coverage and diabetes care; data from the 2000 behavioral risk factor surveillance system. Health Serv Res 2005;40:361-72.

18. Bailey RN, Indian RW, Zhang X, et al. Visual impairment and eye care among older adults - five States, 2005. MMWR Morb Mortal Wkly Rep 2006;55:1321-5.

19. Chou CF, Barker LE, Crews JE, et al. Disparities in eye care utilization among the United States adults with visual impairment: findings from the behavioral risk factor surveillance system 20062009. Am J Ophthalmol 2012;154:S45-S52.e1.

20. McCall DT, Sauaia A, Hamman RF, et al. Are low-income elderly patients at risk for poor diabetes care? Diabetes Care 2004;27:1060-5.

21. Ross JS, Bradley EH, Busch SH. Use of health care services by lower-income and higher-income uninsured adults. JAMA 2006;295:2027-36.

22. Centers for Disease Control and Prevention (CDC). Reasons for not seeking eye care among adults aged $\geq 40$ years with moderateto-severe visual impairment-21 States, 2006-2009. MMWR Morb Mortal Wkly Rep 2011;60:610-3.
23. Li YJ, Xirasagar S, Pumkam C, et al. Vision insurance, eye care visits, and vision impairment among working-age adults in the United States. JAMA Ophthalmol 2013;131:499-506.

24. Paksin-Hall A, Dent ML, Dong F, et al. Factors contributing to diabetes patients not receiving annual dilated eye examinations. Ophthalmic Epidemiol 2013;20:281-7.

25. Messer LC, Laraia BA, Kaufman JS, et al. The development of a standardized neighborhood deprivation index. J Urban Health 2006;83:1041-62.

26. Elliott MN, Fremont A, Morrison PA, et al. A new method for estimating race/ethnicity and associated disparities where administrative records lack self-reported race/ethnicity. Health Serv Res 2008;43(5 Pt 1):1722-36.

27. Storey P, Murchison AP, Dai Y, et al. Comparing methodologies for imputing ethnicity in an urban ophthalmology clinic. Ophthalmic Epidemiol 2014;21:106-10.

28. Early photocoagulation for diabetic retinopathy. ETDRS report number 9 . Early treatment diabetic retinopathy study research group. Ophthalmology 1991;98(5 Suppl):766-85.

29. Klein R, Klein BE, Moss SE. Epidemiology of proliferative diabetic retinopathy. Diabetes Care 1992;15:1875-91.

30. McGwin G, Khoury R, Cross J, et al. Vision impairment and eye care utilization among Americans 50 and older. Curr Eye Res 2010;35:451-8

31. Haire-Joshu D, Glasgow RE, Tibbs TL. Smoking and diabetes. Diabetes Care 2004;27:S74-5.

32. Christen WG, Glynn RJ, Manson JE, et al. A prospective study of cigarette smoking and risk of age-related macular degeneration in men. JAMA 1996;276:1147-51.

33. Bonovas S, Filioussi K, Tsantes A, et al. Epidemiological association between cigarette smoking and primary open-angle glaucoma: a meta-analysis. Public Health 2004;118:256-61.

34. Miller VP, Ernst C, Collin F. Smoking-attributable medical care costs in the USA. Soc Sci Med 1999;48:375-91.

35. Barendregt JJ, Bonneux L, van der Maas PJ. The health care costs of smoking. N Engl J Med 1997;337:1052-7.

36. Giskes K, Kunst AE, Benach J, et al. Trends in smoking behaviou between 1985 and 2000 in nine European countries by education. $J$ Epidemiol Community Health 2005;59:395-401.

37. Heisler M, Piette JD, Spencer M, et al. The relationship between knowledge of recent $\mathrm{HbA} 1 \mathrm{c}$ values and diabetes care understanding and self-management. Diabetes Care 2005;28:816-22.

38. Strauss K, MacLean C, Troy A, et al. Driving distance as a barrier to glycemic control in diabetes. J Gen Intern Med 2006;21:378-80.

39. Zgibor JC, Gieraltowski LB, Talbott EO, et al. The association between driving distance and glycemic control in rural areas. $J$ Diabetes Sci Technol 2011;5:494-500.

40. Littenberg B, Strauss K, MacLean CD, et al. The use of insulin declines as patients live farther from their source of care: results of a survey of adults with type 2 diabetes. BMC Public Health 2006;6:198 